\title{
Propriedades químicas do solo na bacia hidrográfica do rio Vacacaí-Mirim
}

\author{
Chemical soil properties in the river basin of Vacacai-Mirim
}

\author{
Pedro Daniel da Cunha Kemerich¹, Sergio Roberto Martins², Masato Kobiyama ${ }^{3}$, Galileo Adeli Buriol ${ }^{4}$, \\ Willian Fernando de Borba ${ }^{1}$ \\ ${ }^{1}$ Centro de Educação Superior do Norte - RS - CESNORS, Universidade Federal de Santa Maria - UFSM, \\ Linha Sete de Setembro s/n, BR 386 km 40, CEP 98400-000, Frederico Westphalen, RS, BR (eng.kemerich@yahoo.com.br; \\ borba_willian@hotmail.com) \\ 2Universidade Federal da Fronteira Sul - UFFS, Chapecó, SC, BR (sergio@ens.ufsc.br) \\ 3Universidade Federal de Santa Catarina - UFSC, Florianópolis, SC, BR (kobiyama@ens.ufsc.br) \\ ${ }^{4}$ Centro Universitário Franciscano - UNIFRA, Santa Maria, RS, BR (galileo@unifra.br)
}

Recebido em 14 de dezembro de 2012; aceito em 06 de maio de 2013

\begin{abstract}
Resumo
Os teores de metais em solos têm aumentado gradativamente com a modernização da agricultura ocorrida nos últimos anos. A ação antrópica desempenhada pelo homem na natureza é a principal causa desse fenômeno. Com base nisso, o presente estudo tem por objetivo avaliar alterações nos atributos químicos do solo em decorrência de diferentes usos e ocupações na bacia hidrográfica do Rio Vacacaí-Mirim. A técnica utilizada para análise foi a EDXRF, em que os valores foram espacializados com auxílio do software Surfer 10. Os valores de Bário variaram do limite de detecção (LD) a $7.608,27 \mathrm{mg} / \mathrm{kg}^{-1}$ com média de $1.286,71 \pm 2.295,18 \mathrm{mg} / \mathrm{kg}^{-1}$, a concentração de Fósforo variou do LD a $2.327,02 \mathrm{mg} / \mathrm{kg}^{-1}$ com média de $676,45 \pm 700,05 \mathrm{mg} / \mathrm{kg}^{-1}$, Manganês variou do LD a $5.533,51 \mathrm{mg} / \mathrm{kg}^{-1}$ com média de $1.057,34 \pm 1.380,81 \mathrm{mg} / \mathrm{kg}^{-1}$, os valores de Silício variaram de 229.114,70 a $832.568,70 \mathrm{mg} / \mathrm{kg}^{-1} \mathrm{com}$ média de $696.134,25 \pm 144.950,56 \mathrm{mg} / \mathrm{kg}^{-1}$, a concentração de Zinco variou do LD a 429,98 mg/kg-1 com média de $145,725 \pm 123,78 \mathrm{mg} / \mathrm{kg}^{-1}$. Com base nos resultados obtidos, é possível identificar que a concentrações dos metais estudados e os usos do solo estão estritamente ligados, visto que as concentrações são maiores nas áreas que possuem usos agrícolas, que demandam maiores quantidades de produtos químicos. Sendo assim, pôde-se observar que os solos sob os usos de arroz, soja e pastagem apresentaram maior influência na concentração do elemento bário, já o fósforo teve maior influência dos solos sob uso de pastagem e soja.
\end{abstract}

Palavras-chave: Bacia hidrográfica; Contaminação do solo; Metais; Vacacaí-Mirim.

\begin{abstract}
The levels of metals in soils have increased gradually with the modernization of agriculture which has occurred in recent years. The human action performed by man in nature is the main cause of this phenomenon. On this basis, the present study's aim is to evaluate changes in soil chemical properties due to different uses and occupations in the river basin of Vacacaí-Mirim. The technique used for analysis was EDXRF, where the values were spacialized with the aid of the software Surfer 10. Values for Barium ranged from the detection limit (DL) to $7,608.27 \mathrm{mg} / \mathrm{kg}^{-1}$ with an average of $1,286.71 \pm 2,295.18 \mathrm{mg} / \mathrm{kg}^{-1}$, the concentration of Phosphorus ranged from DL to $2,327.02 \mathrm{mg} / \mathrm{kg}^{-1}$ with an average of $676.45 \pm 700.05 \mathrm{mg} / \mathrm{kg}^{-1}$, Manganese ranged from DL to $5,533.51 \mathrm{mg} / \mathrm{kg}^{-1}$ with an average of $1,057.34 \pm 1,380.81 \mathrm{mg} / \mathrm{kg}^{-1}$, the values for Silicon ranged $229,114.70$ to $832,568.70 \mathrm{mg} / \mathrm{kg}^{-1}$ with a mean of $696,134.25 \pm 144,950.56 \mathrm{mg} / \mathrm{kg}^{-1}, \mathrm{Zinc}$ concentration ranged from DL to $429.98 \mathrm{mg} / \mathrm{kg}^{-1}$ with an average of $145.725 \pm 123.78 \mathrm{mg} / \mathrm{kg}^{-1}$. Based on these results, it is possible to identify that the concentrations of the metals studied and the land use are closely linked, since concentrations are higher in areas that have agricultural uses, which require larger amounts of chemicals. Thus, it can be observed that the soils under the uses of rice, soybeans and pasture had greater influence on the concentration of the element barium, phosphorus, however, had most influence by the land use in pasture and soybeans.
\end{abstract}

Keywords: Watershed; Soil contamination; Metals; Vacacaí-Mirim. 


\section{INTRODUÇÃO}

Sabe-se que o solo é um recurso natural lentamente renovável, encontrado em diferentes posições na paisagem. Sua origem resulta da alteração de rochas e sedimentos pela ação das variações climáticas (intensidade das chuvas, variação de temperatura) e dos organismos vivos (fauna e flora), nas mais diversas situações da paisagem ao longo do tempo (Streck et al., 2008).

A dinâmica no mecanismo da formação dos solos traduz-se em processos de fragmentação de natureza físicoquímica das rochas, do transporte da sedimentação e da evolução pedogênica (Rocha, 2005). As características de um determinado solo são determinadas principalmente pelo material de origem e o processo de intemperismo atuante, que formam solos de diferentes atributos físicos e químicos.

A adoção de sistemas conservacionistas de manejo do solo como plantio direto tem-se apresentado como alternativa para contribuir na sustentabilidade econômica e ambiental do agroecossistema (Silva et al., 2000). A variabilidade espacial das características do solo é inerente ao sistema e pode se constituir em fator dominante na interpretação e aplicação dos resultados de análises as práticas de manejo do solo e da água, uma vez que a precisão das análises é mantida em níveis satisfatórios (Coelho, 1983).

A quantificação das alterações nos atributos do solo, decorrentes da intensificação de sistemas de uso e manejo, pode fornecer subsídios importantes para a definição de sistemas racionais de manejo, contribuindo assim para tornar o solo menos suscetível à perda de capacidade produtiva (Neves et al., 2007). Nos últimos anos, aumentou-se a preocupação com a qualidade do solo, na medida em que novas tecnologias são impostas, pode-se resultar em uma diminuição da capacidade em manter uma produção sustentável (Carvalho et al., 2004).

Abreu et al. (2002) apontam os elementos Co, Cd, Cr, $\mathrm{Cu}, \mathrm{Fe}, \mathrm{Hg}, \mathrm{Mn}, \mathrm{Ni}, \mathrm{Pb}$, Sn e $\mathrm{Zn}$ como os principais metais pesados encontrados no solo, presentes através da ação antrópica. A presença dos metais pesados nos solos pode ter origem natural ou antropogênica, sendo que as intervenções do homem sobre a natureza são a principal razão do aumento crescente dos metais pesados nos solos, provocando distúrbios muitas vezes de difícil recuperação para o ambiente (Soares et al., 2011). Nesse contexto, o objetivo do trabalho foi avaliar as alterações químicas do solo em decorrência de diferentes usos e ocupações na bacia hidrográfica do Rio Vacacaí-Mirim.

\section{MATERIAIS E MÉTODOS}

\section{Caracterização da área em estudo}

A bacia hidrográfica do rio Vacacaí-Mirim está localizada na parte central do Estado do Rio Grande do Sul, entre as latitudes de $29^{\circ} 36^{\prime} 55^{\prime \prime} \mathrm{S}$ e $29^{\circ} 39^{\prime} 50^{\prime \prime} \mathrm{S}$ e longitudes de $53^{\circ} 46^{\prime} 30^{\prime \prime} \mathrm{W}$ e $53^{\circ} 49^{\prime} 29^{\prime \prime} \mathrm{W}$, abrangendo uma área total de $1145,7 \mathrm{~km}^{2}$ (Casagrande, 2004). Está inserida em três grandes compartimentos geomorfológicos, com características morfológicas e geológicas distintas: Região do Planalto, do Rebordo do Planalto e da Depressão Central ou Periférica. A Região do Planalto é onde se localizam suas nascentes, à altitude entre 300 e $480 \mathrm{~m}$ e é formada pelo vulcanismo da Bacia do Paraná, ocorrido no Mesozoico, com a presença de basaltos e arenitos intertraps. A região é caracterizada pela presença de um relevo ondulado e suavemente ondulado, resultante do trabalho de dissecação fluvial na superfície do Planalto. A drenagem tem padrão dendrítico, com vales em $\mathrm{V}$ ou de fundo plano.

A área do Rebordo do Planalto localiza-se na transição entre o Planalto e a Depressão Central. A sua topografia caracteriza-se por ser formada por escarpas abruptas, drenagem fluindo no sentido da Depressão Central e padrão dendrítico, com presença marcante de vales em V. A área da Depressão Central ou Periférica é constituída por rochas sedimentares da bacia hidrográfica do rio Paraná, que datam do Paleozoico e Mesozoico (Triássico), encobertas, localmente, por sedimentos cenozoicos e recentes (planícies aluviais). Na região da Depressão Central a topografia é mais ou menos plana e suavemente ondulada, com morros de forma arredondada (Casagrande, 2004).

O clima, na área da bacia hidrográfica, pela classificação climática de Köppen, é do tipo Cfa, subtropical, com chuvas bem distribuídas ao longo do ano e os solos predominantes, de acordo com o atual Sistema Brasileiro de Classificação de Solo (Embrapa, 1999) são, na Região do Planalto os Argissolos vermelho-amarelos Álumínicos, em alguns locais associados aos Neossolos Litólicos, Eutróficos; na Região do Rebordo do Planalto os Neossolos Litólicos, ocorrendo também Chernossolos Argilúvicos e; na Depressão Central, os Planossolos e os Chernossolos Argilúvicos (Casagrande, 2004). A vegetação natural, na área de Planalto e do Rebordo do Planalto, é constituída, predominantemente, por floresta do tipo subtropical e na Depressão Central ou Periférica de campos de pastagem natural. Em meio aos campos, é comum a presença de capões isolados de mata de pequeno e grande porte (SEPLAN, 1986).

\section{Pontos de amostragem}

Para a amostragem do solo, buscou-se locar os pontos visando uma distribuição espacial uniforme na bacia hidrográfica, abrangendo os diferentes tipos de solos existentes, bem como os seus usos predominantes na região em estudo. Dessa maneira, foram amostrados 26 pontos, sendo que estes receberam a nomenclatura variando de 
P1 a P26. A Tabela 1 apresenta os tipos de uso do solo e os pontos de amostragem.

A Tabela 2 apresenta os pontos de amostragem em cada tipo de solo existente na bacia hidrográfica do Rio Vacacaí-Mirim.

A Tabela 3 ilustra a porcentagem referente a cada uso na bacia hidrográfica do Rio Vacacaí-Mirim.

A Figura 1 ilustra a variação altitude na bacia hidrográfica.

O mapa planialtimétrico da Bacia Hidrográfica do Rio Vacacaí-Mirim (Figura 1) demonstra a ocorrência de áreas com altitudes iguais ou inferiores a $50 \mathrm{~m}$ na região Sudeste que é ocupada principalmente pela cultura do arroz (Várzea do Rio Vacacaí-Mirim). Altitudes na ordem de $100 \mathrm{~m}$ ocorrem principalmente na região central e oeste, já as maiores altitudes situam-se na região noroeste da Bacia Hidrográfica variando entre 150 e $450 \mathrm{~m}$.

Tabela 1. Uso e ocupação do solo na Bacia Hidrográfica do Rio Vacacaí-Mirim.

\begin{tabular}{lc}
\hline Usos do solo & Pontos de amostragem \\
\hline Mata Nativa & $1,2,3,10,26$ \\
Campo Nativo & $5,12,22,23$ \\
Pastagem & $11,15,20$ \\
Soja & $4,6,7,8,9$ \\
Arroz & $16,17,18,19,21,24,25$ \\
Área Urbana & 13,14 \\
\hline
\end{tabular}

Tabela 2. Tipos de solo na Bacia Hidrográfica do Rio Vacacaí-Mirim.

\begin{tabular}{lc}
\hline Tipo de solo & Pontos de amostragem \\
\hline Argissolo Bruno-Acinzentado & 20,21 \\
álico ou alumínico & 8 \\
Argisolo Bruno-Acinzentado & $2,7,9,10$ \\
álico & 22,23 \\
Neosolos Litólicos eutróficos & e distróficos \\
Argissolo Vermelho álico e & $1,3,4,5,6,13,14,15$, \\
distrófico & 25,26 \\
Planossolo Háplico Eutrófico & $11,12,16,17,18,24$, \\
\hline
\end{tabular}

Tabela 3. Porcentagem referente a cada uso do solo na bacia hidrográfica do Rio Vacacaí-Mirim.

\begin{tabular}{lcc}
\hline Uso do solo & Área (ha) & Área (\%) \\
\hline Área Urbana & $2.974,73$ & 2,51 \\
Arroz & 33.916 & 28,67 \\
Soja & $13.076,29$ & 11,05 \\
Solo Exposto & $16.149,25$ & 13,65 \\
Floresta & $14.811,09$ & 12,52 \\
Lâmina D'água & $2.147,16$ & 1,81 \\
Campo/Pastagem & $35.242,21$ & 29,79 \\
\hline
\end{tabular}

\section{Caracterização geológica da área de estudo}

Segundo Hentges (2009), na bacia hidrográfica do rio Vacacaí-Mirim, foram analisados os Mapas geológicos da Folha de Santa Maria e Camobi, onde foram encontradas as seguintes formações geológicas: Formação Sanga do Cabral, Formação Santa Maria com os Membros Alemoa e Passo das Tropas, a Formação Caturrita, a Formação Botucatu, a Formação Serra Geral, os Depósitos Fluviais e Terraços (Figura 2).

Na região das nascentes da bacia, em sua porção de cotas altimétricas mais elevadas, ocorre a Formação Serra Geral. De acordo com o Mapa Geológico da CPRM (2008) esta é constituída de derrames de rochas vulcânicas básicas (basaltos, teor em $\mathrm{SiO}_{2}$ entre $45-52 \%$ ) e rochas ácidas (riólitos, riodacitos, granófiros com teor em $\mathrm{SiO}_{2}$ entre $52-55 \%$ ) Leinz e Amaral (1989). A diferença mais importante nessas duas unidades reside no seu padrão de fraturas/diáclases, sendo as rochas ácidas com padrão tabular, horizontal, enquanto as básicas com padrão poliédrico, que favorece a esfoliação esferoidal e a infiltração de águas meteóricas tanto nas maciças quanto nas amigdaloides (pedra sapo), e também diáclases verticais. Algumas dessas são abertas e facilitam a infiltração da água da chuva e a recarga subterrânea (Silva et al., 2004).

Nessa unidade localizam-se os cultivos de soja, áreas de floresta e pastagem. Já na região oeste da bacia localizam-se as regiões de várzeas onde predomina o cultivo de arroz, compreendido pela formação a partir de sedimentos atuais (aluviões).

As sequências de rochas sedimentares arenosas clásticas com diferentes relações entre porosidade e permeabilidade, ocorrem na Depressão Periférica do Estado do Rio Grande do Sul, e na região próxima da cidade de Santa Maria, conforme descritas:

a) Formação Sanga do Cabral - ocorre em corpos tabulares ou lenticulares alongados, brecha e conglomerado intraformacional, siltito e raro argilito, ambiente continental, fluvial entrelaçado, contendo fragmentos de vertebrados fósseis anfíbios e répteis. Segundo a CPRM (1994), trata-se de um Aquitardo proporcionando baixas vazões nos poços, sendo a água de boa qualidade. Hentges (2009) diz que a intemperização dessa rocha é caracterizada por descoloração, maior fragmentação próxima à superfície topográfica seguindo a estratificação e diáclases. Num estágio mais avançado, o aspecto é um amontoado de fragmentos angulosos a semiangulosos de cores variadas.

b) Formação Caturrita - constituída por arenitos, conglomerados, siltito arenoargiloso e folhelho, contendo tetrápodes fósseis e troncos de coníferas, ambiente continental depósitos fluviais e deltas lacustres, ex. Monumento do Imigrante, estrada Santa Maria para o Município de Silveira Martins. A faixa de altitude média em que ocorre está compreendida entre 120 e 210 m, embora na 
porção leste da Folha de Camobi e em direção a Silveira Martins, o topo da Unidade situa-se até $260 \mathrm{~m}$ de altitude, devido à falhamentos (Hentges, 2009).

c) Formação Botucatu - constituída de arenito fino a grosso, grãos bem arredondados e alta esfericidade, dispostos em sets e cosets de estratificação cruzada de grande porte. Paleoambiente continental desértico, depósitos de dunas eólicas. De acordo com CPRM (1994), formam excelentes reservatórios aquíferos. Paleoambiente continental de canais fluviais. Hentges (2009) diz que a área de ocorrência desta Formação limita-se a uma faixa relativamente estreita constituindo a porção média a basal do rebordo do Planalto e dos morros testemunhos da região serrana.

d) Formação Santa Maria, Membro Passo das Tropas - arenitos e arenitos conglomeráticos com pelitos subordinados, contendo elementos da Flora dicroidium. CPRM (1994) cita como o melhor aquífero da região, excelentes vazões e águas em geral de boa qualidade, porém muito vulnerável à poluição. $\mathrm{O}$ Membro Alemoa constituído por siltito-argilosos vermelhos, maciços, contendo fauna de Tetrapodes fósseis e concreções carbonáticas (calcretes). Paleoambiente com depósitos lacustres. De acordo com CPRM (1994), não são aquíferos, portanto Aquicludes (não armazena nem transmite a água). Exemplos ocorrem em vários pontos da cidade de Santa Maria a qual forneceu o nome da unidade devido a sua secção-tipo e a ocorrência de fósseis. O Membro Passo das Tropas é constituído, predominantemente por arenitos grosseiros a médios, de cores amarela e rosa-avermelhada, às vezes com tonalidade púrpura, feldspáticos, por vezes conglomeráticos com seixos e grânulos de quartzo, constituindo corpos lenticulares com estratificação cruzada acanalada e planar de grande porte. Esses arenitos se intercalam com camadas de siltitos arenosos de cores vermelha e púrpura indicativos de ambiente fluvial (Hentges, 2009).

e) Depósitos (aluviões) e terraços fluviais - a CPRM (1994) descreve os Aluviões como aquíferos contínuos de grande extensão, livre. Constitui-se de sedimentos clásticos não consolidados, de pequena espessura (máximo de $10 \mathrm{~m}$ ) Permeabilidade alta, com água de boa qualidade. Muito vulnerável à poluição. Já os Terraços Fluviais são constituídos por conglomerados, arenitos médios a argilosos, siltitos arenosos fluviais. Aquífero irregular livre, constituídos por sedimentos pouco consolidados bastante argilosos, de pequena espessura. A permeabilidade é de média a baixa. A água é de boa qualidade. $\mathrm{O}$ aproveitamento é realizado por poços escavados. A área de ocorrência desses depósitos sedimentares acompanha as margens do Arroio Grande, do Arroio do Meio e do Rio Vacacaí, na porção sul-sudeste da Folha, na forma de terraços fluviais, situados numa altura variável em torno de 10 - $20 \mathrm{~m}$ acima das planícies aluviais recentes (Hentges, 2009).

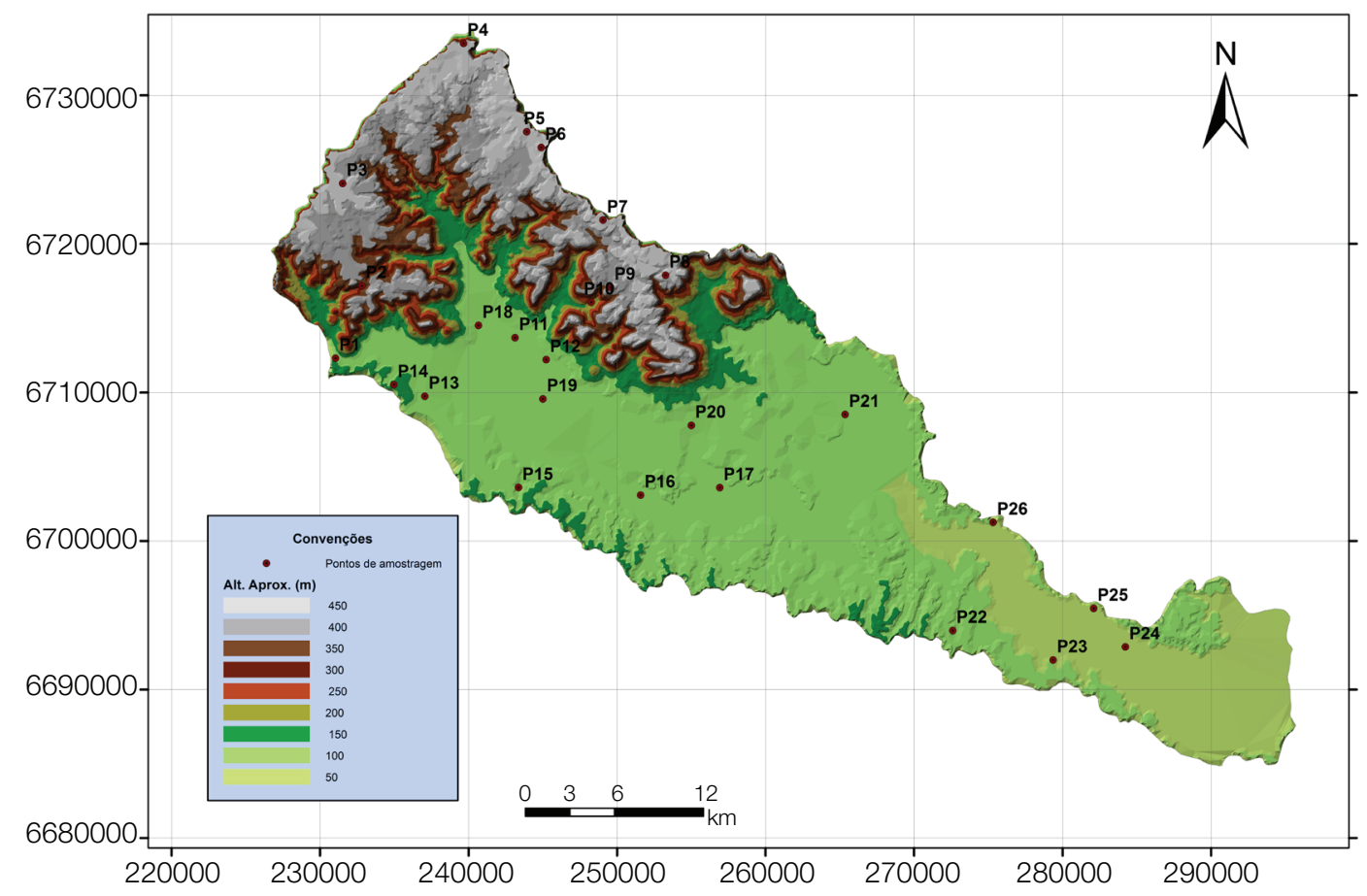

Figura 1. Mapa Planialtimétrico da Bacia Hidrográfica do Rio Vacacaí-Mirim, RS. 


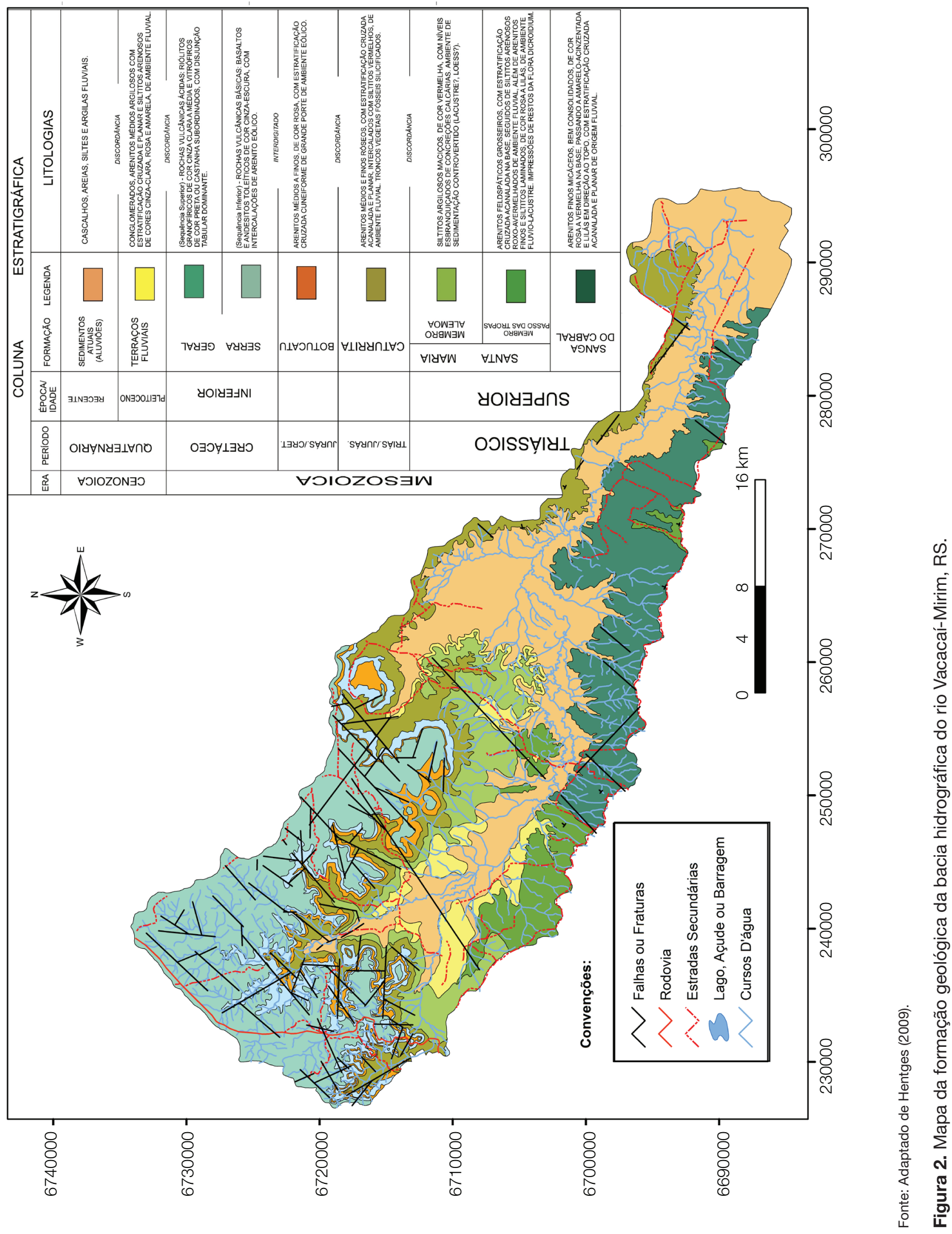




\section{Preparo das amostras e determinação dos metais}

Foram pesadas $20 \mathrm{~g}$ de solo e encaminhadas para a secagem em estufa à temperatura de $105^{\circ} \mathrm{C}$ por duas horas, utilizando-se vidraria básica de laboratório (Becker $50 \mathrm{~mL}$ ) para sua deposição. Após o quarteamento e a secagem em estufa, as amostras foram moídas manualmente em gral com pistilo, objetivando reduzir ao máximo a granulometria da amostra reduzindo os desvios do feixe de Raios- $\mathrm{X}$ e, assim, não influenciando na eficiência das determinações.

As amostras de solo foram então comprimidas em prensa manual em matriz apropriada, formando uma pastilha sólida e compacta que foi encaminhada para a análise. A pastilha foi formada usando 10 toneladas de pressão por 10 minutos. Esse procedimento aglomera as partículas tornando-as um aglomerado cerâmico cujo resultado analítico reflete-se num padrão ideal para análise por EDXRF.

As análises foram realizadas utilizando um Espectrômetro de Fluorescência de Raios-X por Energia Dispersiva, do modelo Shimadzu EDX-720. As seguintes condições de operação do equipamento foram selecionadas: tensão do tubo de $15 \mathrm{keV}$ ( $\mathrm{Na}$ a Sc) e $50 \mathrm{keV}$ ( $\mathrm{Ti}$ a $\mathrm{U}$ ) com corrente no tubo $184 \mu \mathrm{A}$ e $25 \mu \mathrm{A}$ respectivamente, colimador de $10 \mathrm{~mm}$, tempo morto do detector de $40 \%$ e $39 \%$, sob vácuo e detector de $\mathrm{Si}$ (Li) refrigerado com nitrogênio líquido (Pataca et al., 2005), tempo real de integração de 200 segundos, diferentemente do utilizado por Wastowski et al. (2010) que utilizaram $300 \mathrm{~s}$. O método analítico usado é denominado método dos Parâmetros Fundamentais (FP). Esse método permite a obtenção da curva de sensibilidade do equipamento para cada elemento de interesse. Quando uma amostra de composição química conhecida é submetida a parâmetros instrumentais bem definidos, a curva de sensibilidade do equipamento relaciona a intensidade fluorescente teórica calculada e a medida para cada elemento (Bona et al., 2007; Wastowki et al., 2010).

\section{Espacialização dos resultados}

Para a realização dos mapas foi utilizado o software Surfer 10; como método de elaboração matemática foi utilizada a krigagem. Inicialmente foram lançados os valores para ponto de amostragem de solo (com o metal a ser espacializado) com as coordenadas UTM (Universal Transverse Mercator) escolhendo-se a opção Countor Map e gerandose um cartograma de contorno da superfície da área estudada, logo após foram espacializadas as informações de interesse com o uso da opção Post Map.

\section{RESULTADOS E DISCUSSÃO}

\section{Bário (Ba)}

Na Bacia Hidrográfica do Rio Vacacaí-Mirim, os valores de Bário total variaram entre valores menores que o limite de detecção (LD) a $7.608,27 \mathrm{mg} / \mathrm{kg}^{-1}$ com média de $1.286,71$ $\pm 2.295,18 \mathrm{mg} / \mathrm{kg}^{-1}$. Como pode ser observado na Figura 3, os maiores valores estão presentes nas regiões leste e sudeste com uma concentração máxima no ponto $21(7.608,27$ $\left.\mathrm{mg} / \mathrm{kg}^{-1}\right)$; já os menores valores encontram-se na região norte e oeste (pontos P1, P2, P3, P4, P5, P6, P7, P8, P9, P10, P12, P13, P14, P15, P17, P20 e P26) com concentrações menores que o LD. Conforme a Resolução $n^{\circ}$ 420/2009 do CONAMA, que considera o limite de prevenção de Bário no solo de $150 \mathrm{mg} / \mathrm{kg}^{-1}$, os pontos P11 (área de pastagem), P16, P18,P19, P21, P24 e P25 (cultivo de arroz) pontos P22 e P23 (campo nativo) encontram-se acima do valor médio permitido (VMP) por essa resolução.

Kemerich et al. (2012), usando a técnica de EDXRF, estudando um solo da região noroeste do estado do Rio Grande do Sul, encontraram valores de Ba variando de 2.730 a $15.132 \mathrm{mg} / \mathrm{kg}^{-1}$, valores esses acima dos encontrados neste estudo.

Os problemas ambientais gerados pela agricultura, relativos à contaminação de solo por metais pesados, por exemplo, decorrem do uso intensivo de agrotóxicos e fertilizantes; daí a relevância da determinação e do monitoramento desses metais como um indicador de sustentabilidade (Bacellar et al., 2003). A concentração de Ba no solo, em escala mundial, varia de 19 a $2.368 \mathrm{mg} / \mathrm{kg}^{-1}$, podendo ser mobilizado em diferentes condições (Kabata-Pendias e Pendias, 1992). No estudo, esses valores encontram-se acima do descrito anteriormente por levar em consideração as concentrações totais do elemento no solo.

O Ba ocorre naturalmente somente na forma combinada, sendo que as duas principais são a barita (sulfato de bário natural) e a witherita (carbonato de bário natural). Esse elemento também é encontrado em quantidades-traço em rochas ígneas e sedimentares. A barita é a principal fonte de obtenção de bário metálico que, juntamente com seus compostos, são usados na fabricação de diversos produtos industriais, como plásticos, vidros, cerâmicas, eletrônicos, têxteis, lubrificantes, ligas metálicas, sabão e borracha. Com relação às emissões antropogênicas, essas podem ocorrer a partir da mineração, refino e tratamento de minérios de bário e da fabricação de produtos de bário (CETESB, 2012). $\mathrm{Na}$ área de estudo, os maiores valores desse elemento podem estar relacionados com a ação antropogênica nos usos que demandam produtos químicos ou até mesmo fertilizantes que contêm esse elemento em sua composição.

\section{Fósforo (P)}

Na bacia hidrográfica do Rio Vacacaí-Mirim, os valores de Fósforo total variaram entre menores que o $\mathrm{LD}$ a $2.327,02 \mathrm{mg} / \mathrm{kg}^{-1}$ com média de $676,45 \pm 700,05 \mathrm{mg} / \mathrm{kg}^{-1}$. Como pode ser observado na Figura 4, os maiores valores estão na região oeste com concentração máxima ocorrendo no P11, sob uso de pastagem $\left(2.327,02 \mathrm{mg} / \mathrm{kg}^{-1}\right)$; já os menores valores encontram-se nas regiões sudeste e sudoeste, 


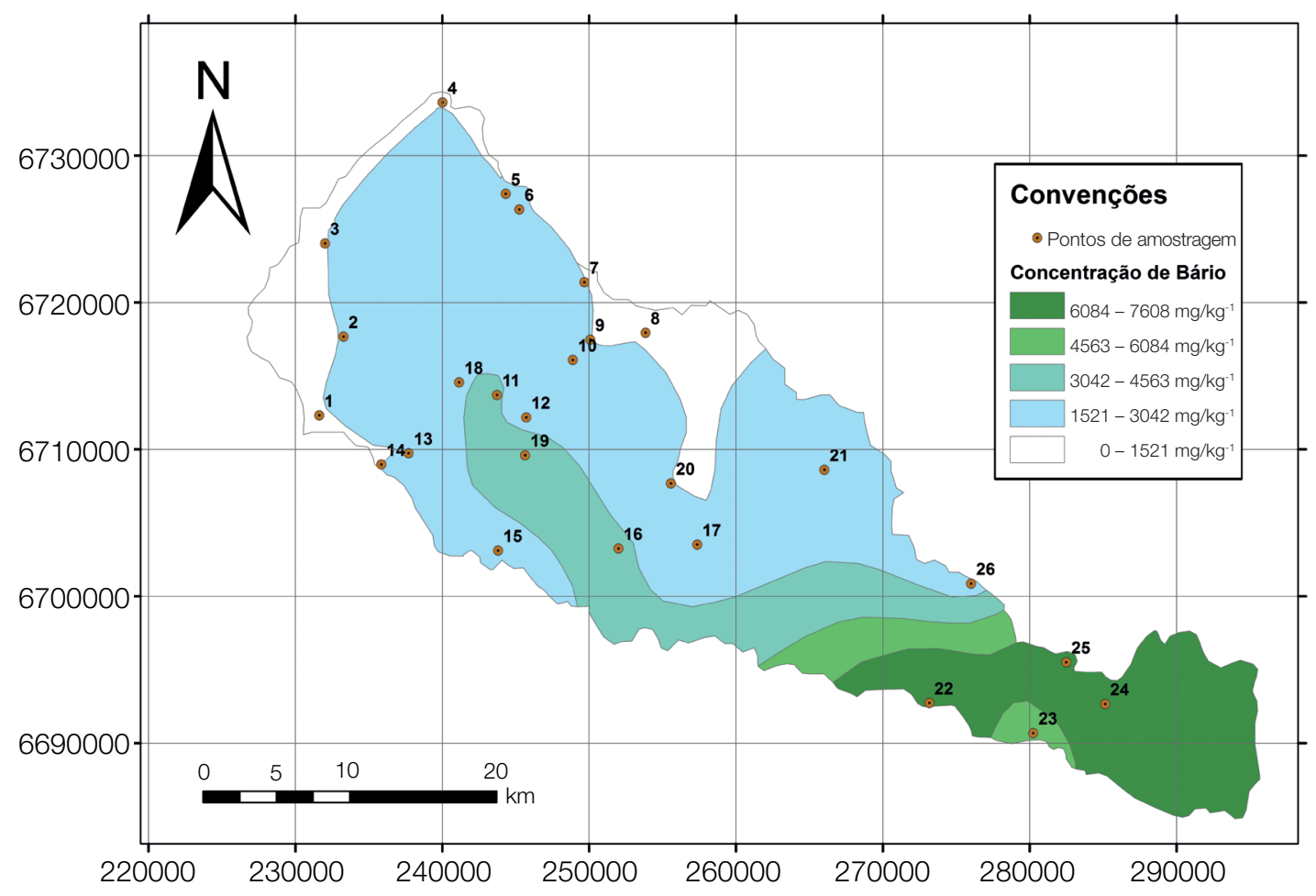

Figura 3. Concentração de Bário na Bacia Hidrográfica do Rio Vacacaí-Mirim, RS.

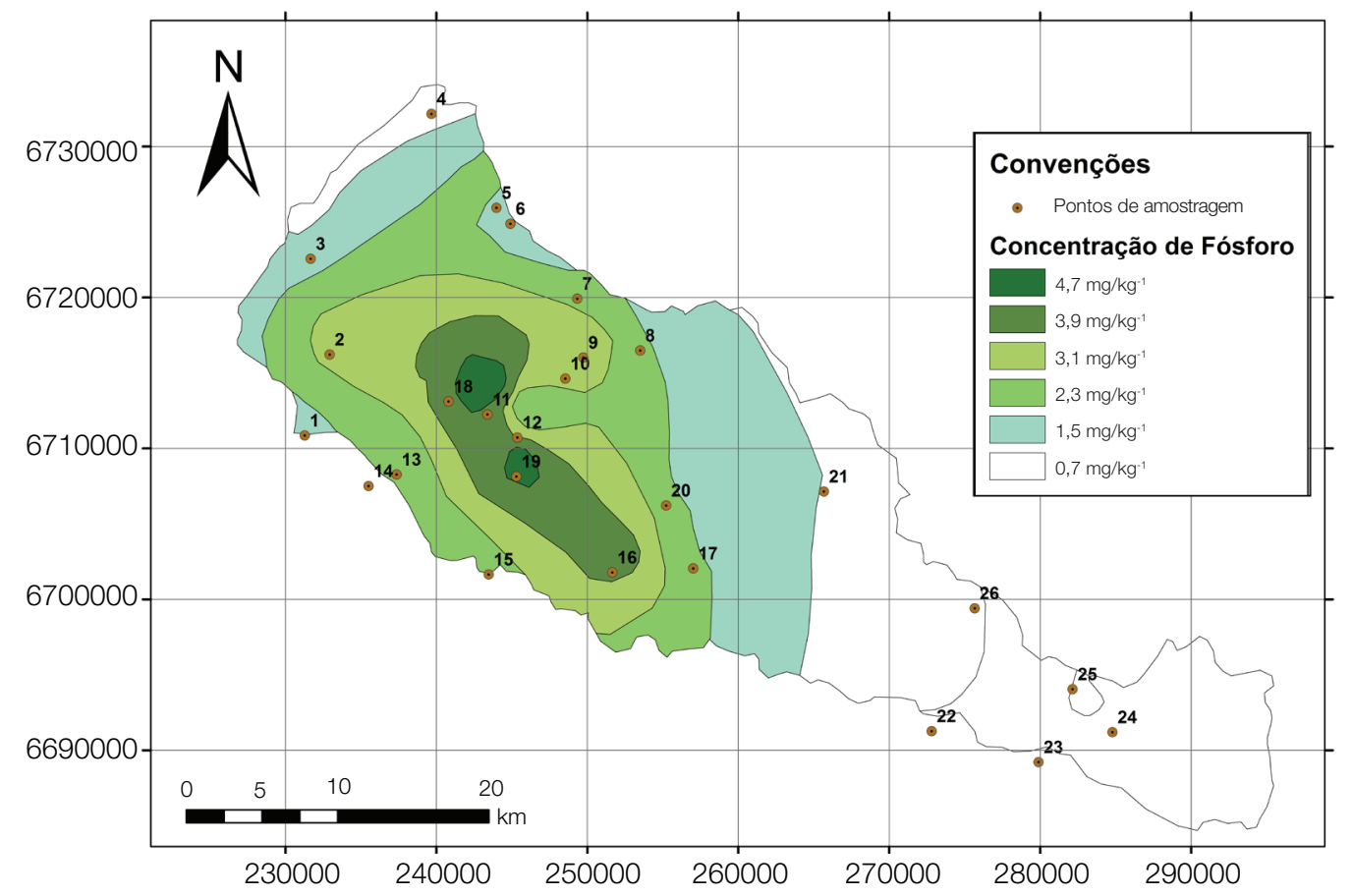

Figura 4. Concentração de Fósforo na Bacia Hidrográfica do Rio Vacacaí-Mirim, RS. 
com valores inferiores ao $\mathrm{LD}$, sendo representado pelos pontos P1 (mata nativa), P13 (área urbana), P15 (pastagem), P17, P19, P23, P24, P25 (cultivo de arroz) e P22 (campo nativo). Com relação a esse elemento, destaca-se como a principal entrada do mesmo no solo o uso de fertilizantes, explicando o fato das maiores concentrações estarem presentes em solo de pastagem.

As concentrações médias para os usos de campo nativo, mata nativa e soja encontradas na área de estudo, foram de $277 \mathrm{mg} / \mathrm{kg}^{-1}, 978 \mathrm{mg} / \mathrm{kg}^{-1}$ e $1.194 \mathrm{mg} / \mathrm{kg}^{-1}$, respectivamente. Valores estes que foram semelhantes aos encontrados por Wastowski et al. (2010), usando a técnica de EDXRF, na cidade de Frederico Westphalen - RS para os usos de mata nativa e cultivo de soja, em que as concentrações médias foram de $810 \mathrm{mg} / \mathrm{kg}^{-1}$ e $1.085 \mathrm{mg} / \mathrm{kg}^{-1}$, respectivamente. Já para o uso de campo nativo, os valores descritos pelos mesmos autores $\left(835 \mathrm{mg} / \mathrm{kg}^{-1}\right)$ apresentam-se acima dos presentes na bacia hidrográfica do Rio VacacaíMirim. O fósforo pode ser adicionado ao solo como adubo comercial (químico), esterco de curral ou de galinha, lodo de esgoto, restos de colheita ou outros subprodutos. Essas práticas, porém, não são suficientes, havendo necessidade de usar outras fontes (MINEROPAR, 2004). A adesão dessas fontes secundárias de $\mathrm{P}$, muitas vezes acarretam em um aumento prejudicial ao solo e aos recursos hídricos, pois com ação da chuva são carreados até os rios ou infiltram até o lençol freático.

Marcolan (2006) afirma que, na prática do plantio direto, esse elemento fica acumulado na superfície do solo decorrente da aplicação dos adubos na camada superficial. Sendo assim, fica mais vulnerável ao carreamento pela ação da água. O aumento das concentrações de $\mathrm{P}$ e Nitrogênio nos corpos d'água acarretam um processo chamado eutrofização, que prejudica não só a qualidade da água, mas também os organismos que habitam o meio aquático.

\section{Manganês (Mn)}

Os valores de Mn total variaram do LD a 5.533,51 mg/ $\mathrm{kg}^{-1}$ com média de $1.057,34 \pm 1.380,81 \mathrm{mg} / \mathrm{kg}^{-1}$. Na Figura 5 os maiores valores estão presentes nas regiões oeste e noroeste, com o valor máximo encontrado no P9 (cultivo de soja) com concentração de $5.533,51 \mathrm{mg} / \mathrm{kg}^{-1}$; enquanto os menores valores estão nas regiões norte e sudeste, onde os valores foram menores que o LD (nos pontos P22 (campo nativo), P24 e P25 (cultivo de arroz)).

Valores semelhantes foram encontrados em SeberiRS por Kemerich et al. (2011), utilizando a técnica de EDXRF, onde a concentração de Mn variou de 882,49 a $4.163,44 \mathrm{mg} / \mathrm{kg}^{-1} \mathrm{em}$ nove pontos de amostragem. Para os usos de campo nativo, mata nativa eárea de cultivo de arroz, a concentração média foi de $1000 \mathrm{mg} / \mathrm{kg}^{-1}, 1727 \mathrm{mg} / \mathrm{kg}^{-1}$ e $1550 \mathrm{mg} / \mathrm{kg}^{-1}$, respectivamente. Wastowski et al. (2010), usando a técnica de EDXRF, encontraram para os mesmos usos de solo na cidade de Frederico Westphalen RS, valores médios bem acima dos descritos no presente trabalho $\left(3.950 \mathrm{mg} / \mathrm{kg}^{-1}, 4.620 \mathrm{mg} / \mathrm{kg}^{-1}\right.$ e $3.720 \mathrm{mg} / \mathrm{kg}^{-1}$ respectivamente).

O Manganês (Mn) possui densidade de $7,40 \mathrm{~g} / \mathrm{cm}^{-3}$ e peso atômico $25 \mathrm{~g}$. As principais fontes são Pirosulita ou Manganês Mole, Psilomelana ou Manganês Duro e Rodocrosita. O Manganês é um micronutriente essencial para todos os organismos e raramente ocorre em concentrações perigosas, pois é essencial na produção da clorofila e tem papel como ativador enzimático (MINEROPAR, 2005). Esse elemento químico é muito usado na manufatura do aço, de compostos químicos, pilhas, eletrodos para solda em ligas com o Níquel e o Cobre, bem como na indústria de fertilizantes e fungicidas (Paes, 2003). Isso explica a alta concentração desse elemento na área de cultivo de soja.

\section{Silício (Si)}

As concentrações de Silício total das 26 amostras variaram de $229.114,70$ a $832.568,70 \mathrm{mg} / \mathrm{kg}^{-1}$ com média de $696.134,25 \pm 144.950,56 \mathrm{mg} / \mathrm{kg}^{-1}$. Como pode ser observado na Figura 6, os maiores valores estão presentes nas regiões sudeste e norte, incluindo o valor máximo no ponto P24 (cultivo de arroz). Os menores valores estão nas regiões sudeste e noroeste com valor mínimo no ponto 21 (cultivo de arroz) com concentração de 229.114,70 mg/ $\mathrm{kg}^{-1}$.

$\mathrm{O} \mathrm{Si}$, depois do $\mathrm{O}_{2}$, é o elemento mais abundante da crosta terrestre e, mesmo não sendo considerado elemento essencial para o desenvolvimento das plantas, sua absorção pode ocasionar benefícios para culturas acumuladoras desse elemento, como o arroz (Mengel e Kirkby, 1987).

$\mathrm{O}$ óxido de silício $\left(\mathrm{SiO}_{2}\right)$ é o mineral primário mais abundante nos solos, constituindo a base da estrutura da maioria dos argilominerais. Todavia, em razão do avançado grau de intemperização em que se encontram os solos das regiões tropicais, o $\mathrm{Si}$ é encontrado basicamente na forma de quartzo, opala $\left(\mathrm{SiO}_{2} \cdot \mathrm{nH}_{2} \mathrm{O}\right)$ (Barbosa Filho et al., 2001).

Desse modo os solos tropicais são, de modo geral, altamente intemperizados, sendo que os minerais primários facilmente intemperizáveis que contêm $\mathrm{Si}$ são quase inexistentes. Esses solos apresentam, em alguns casos, teores menores do que $2 \mathrm{mg} / \mathrm{kg}^{-1}$ no extrato saturado (Fonseca, 1999).

Para a cultura do arroz, Mauad et al. (2003) explicam que esse elemento é essencial, sendo de fundamental importância para a estrutura da planta, melhores rendimentos produtivos e resistência a doenças. 


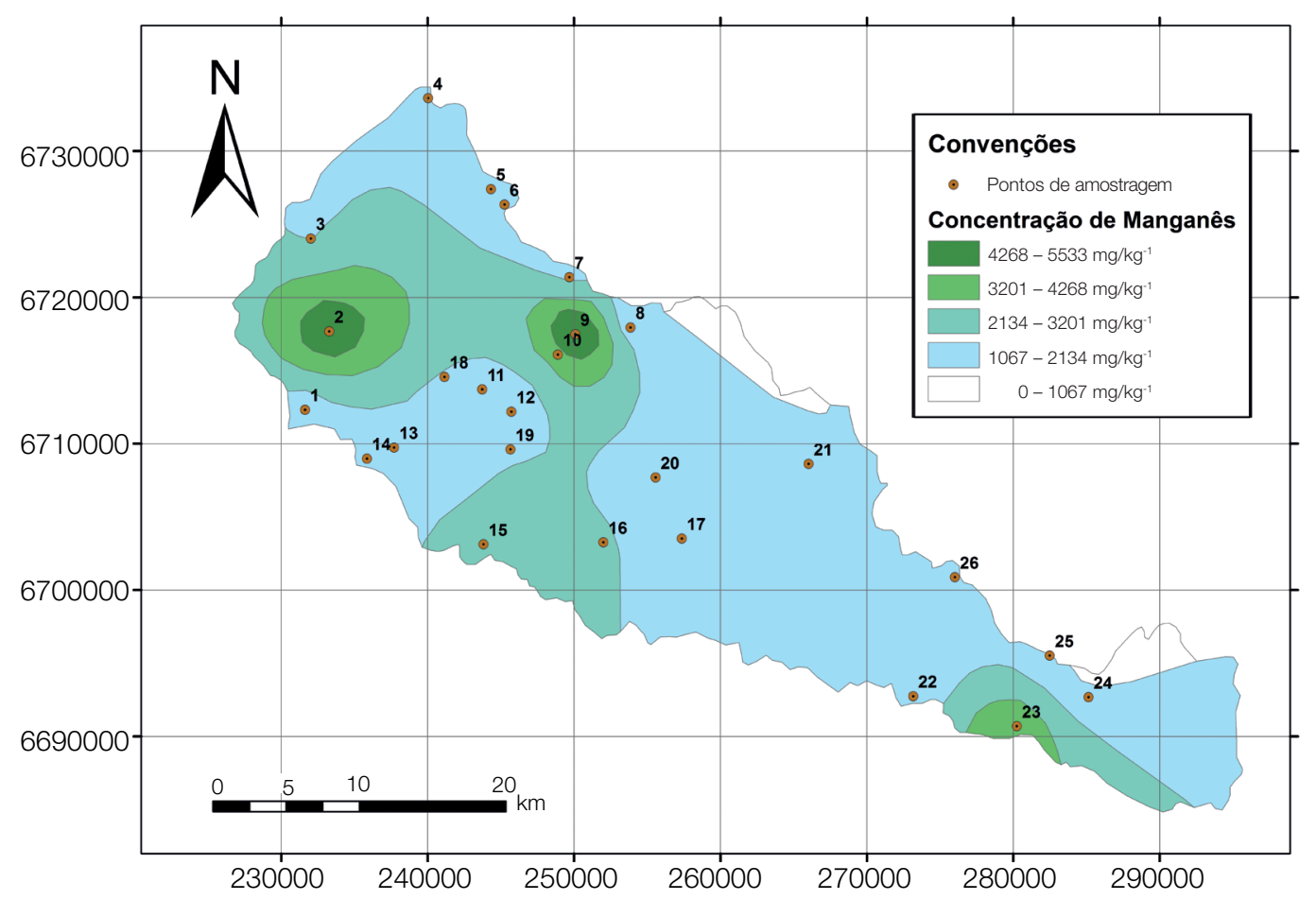

Figura 5. Concentração de Manganês na Bacia Hidrográfica do Rio Vacacaí-Mirim, RS.

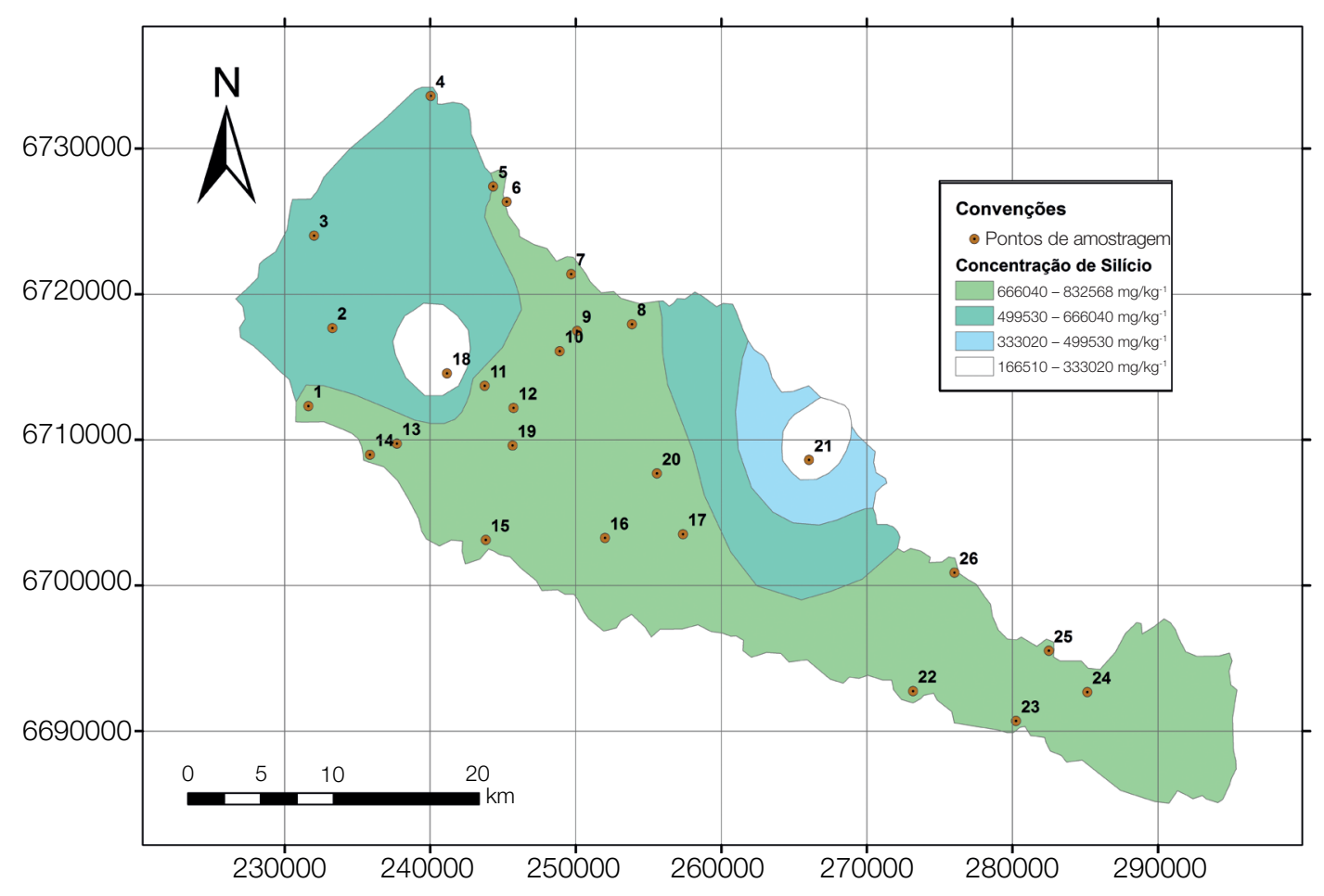

Figura 6. Concentração de Silício na Bacia Hidrográfica do Rio Vacacaí-Mirim, RS. 


\section{Zinco (Zn)}

Os valores de $\mathrm{Zn}$ total variaram de valores menores que o LD a 429,98 mg/ $\mathrm{kg}^{-1}$ com média de 145,72 $\pm 123,78 \mathrm{mg} / \mathrm{kg}^{-1}$. Como pode ser observado na Figura 7, os maiores valores estão presentes na região noroeste, cuja concentração máxima é de $429,97 \mathrm{mg} / \mathrm{kg}^{-1}$. Os menores valores estão nas regiões nordeste, sul e oeste, a uma concentração menor que o LD.

$\mathrm{O}$ menor valor para $\mathrm{Zn}$ ocorreu no ponto P13 (área urbana) onde a concentração foi menor que o LD; enquanto o maior foi no ponto P2 $\left(429,97 \mathrm{mg} / \mathrm{kg}^{-1}\right)$, em uma área de mata nativa. Conforme a Resolução $n^{\circ} 420 / 2009$ do CONAMA, que estabelece limite de prevenção de Zinco no solo de $300 \mathrm{mg} / \mathrm{kg}^{-1}$, os pontos P2 e P3 (mata nativa), P4 e P9 (soja) apresentaram valores superiores ao VMP.

Os valores médios para os usos de mata nativa e cultivo de soja foram de $250 \mathrm{mg} / \mathrm{kg}^{-1}$ e $198 \mathrm{mg} / \mathrm{kg}^{-1}$, respectivamente. Valores semelhantes foram descritos por Wastowski et al. (2010) para esses mesmos usos $\left(245 \mathrm{mg} / \mathrm{kg}^{-1}\right.$ e $\left.210 \mathrm{mg} / \mathrm{kg}^{-1}\right)$; porém, para a área de campo nativo, o valor médio descrito pelos mesmos autores $\left(180 \mathrm{mg} / \mathrm{kg}^{-1}\right)$ apresentou-se acima do encontrado na área de estudo $\left(88 \mathrm{mg} / \mathrm{kg}^{-1}\right)$. Tito et al. (2011) dizem que a maioria da incorporação de zinco no solo se dá através da ação antrópica (fertilizantes e pesticidas), que se agrava ainda mais quando são aplicados em produtos que serão utilizados diretamente na alimentação humana (grãos e hortaliças).

$\mathrm{O}$ elemento químico Zinco tem densidade $7,10 \mathrm{~g} / \mathrm{cm}^{-3}$ e peso atômico 30 e ocorre na Esfarelita (ou Blenda de Zinco) encontrada associada ao sulfeto de Chumbo e à Smithsonita. O Zinco é um elemento-traço essencial em todos os sistemas vivos, desempenhando um papel importante nas atividades enzimáticas, no metabolismo dos ácidos nucleicos, na síntese de proteínas, manutenção da estrutura e função das membranas, atividade hormonal, reprodução e maturidade sexual. Animais com deficiência de Zn necessitam de $50 \%$ mais alimentos para adquirir o mesmo que peso que os animais com suplemento adequado do metal (MINEROPAR, 2005).

Grande parte do Zn presente no solo encontra-se ligado e, sendo assim, não se dissolve na água. Entretanto, dependendo das características do solo, parte do metal pode alcançar águas subterrâneas. A contaminação dessas águas a partir de sítios de descarte tem sido relatada na literatura (Azevedo e Chasin, 2003). Segundo Pelozato (2008), o Zn pode ser encontrado no ar, no solo, na água e está naturalmente presente nos alimentos. Produtos marinhos, grãos, carnes, laticínios, legumes e nozes apresentam altos teores de zinco.

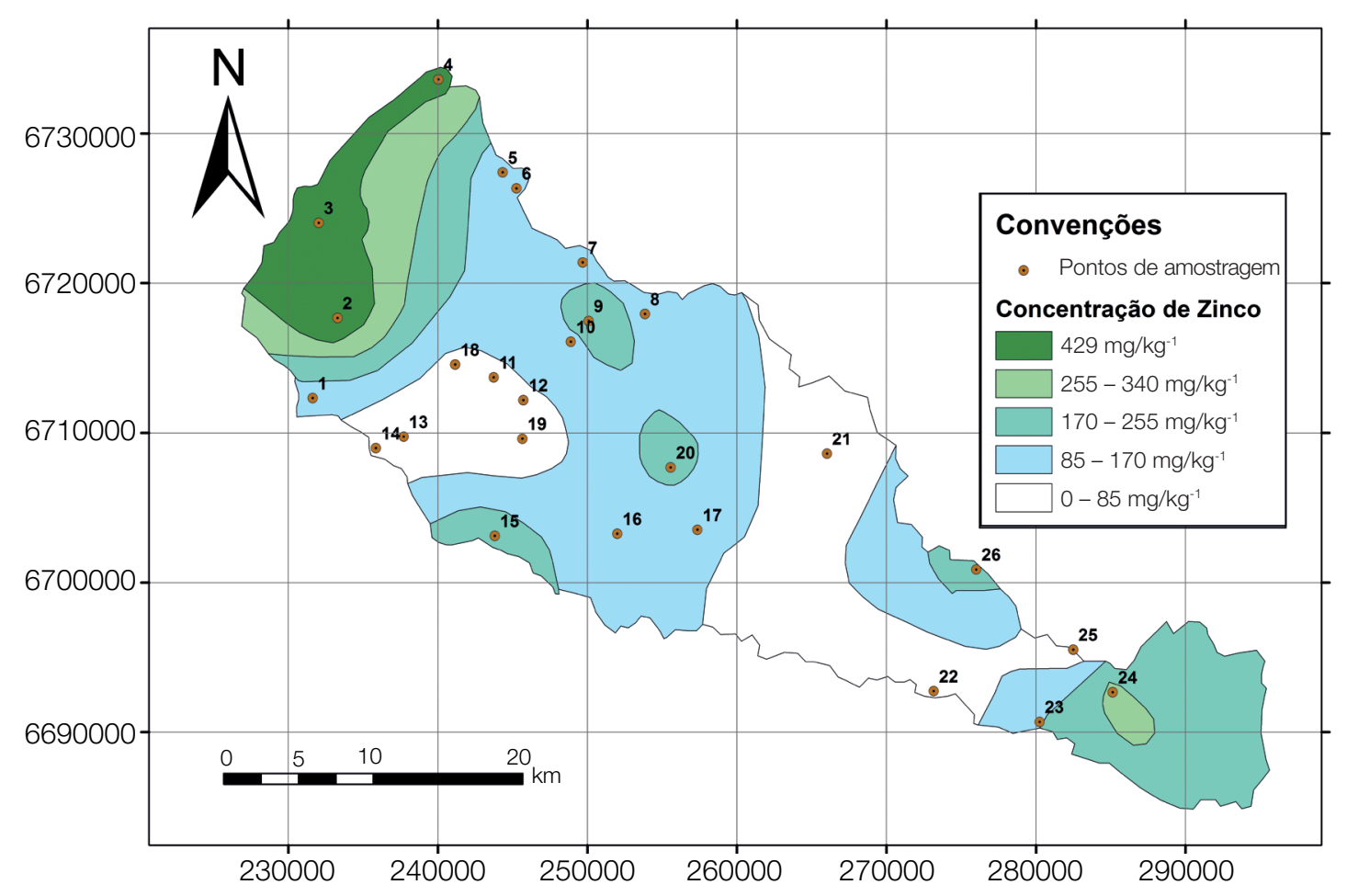

Figura 7. Concentração de Zinco na Bacia Hidrográfica do Rio Vacacaí-Mirim, RS. 


\section{Correlação e análise estatística dos parâmetros analisados}

A Tabela 4 ilustra a correlação entre os parâmetros analisados, sendo que os valores destacados apresentaram correlação.

Como pode ser observado na Tabela 4 , a altitude apresentou correlação com os elementos $\mathrm{Zn}(0,43)$ e $\mathrm{P}(0,39)$, indicando a ocorrência nas regiões mais elevadas da bacia hidrográfica. $\mathrm{O}$ resultado da correlação entre a altitude e $\mathrm{o}$ elemento $\mathrm{Ba}(-0,42)$ indica a ocorrência de maiores concentrações nas áreas mais baixas. Entre os elementos químicos estudados, o $\mathrm{Zn}$ apresentou correlação direta com Mn $(0,53)$.

A Tabela 5 ilustra a análise estatística da concentração $\left(\mathrm{mg} / \mathrm{kg}^{-1}\right)$ dos elementos químicos $(\mathrm{Ba}, \mathrm{Mn}, \mathrm{P}$, $\mathrm{Si}$ e $\mathrm{Zn}$ ) em relação aos usos do solo (área urbana, arroz, campo nativo, mata nativa, soja e pastagem) para o teste Duncan ao nível de 5\% de probabilidade. Para o elemento bário, os solos ocupados por arroz, soja e pastagem apresentaram uma maior influência na concentração desse elemento, diferenciando-se estatisticamente dos solos ocupados por área urbana, campo nativo e mata nativa, onde as concentrações foram menores. Já para o elemento fósforo, os solos ocupados por pastagem e soja apresentaram uma maior influência na concentração do elemento. Solos ocupados por mata nativa, campo nativo e arroz não apresentaram diferença estatística entre si. O mesmo ocorreu para os solos de campo nativo, arroz e área urbana, para esse elemento. Os demais elementos (Mn, Si e Zn) não apresentaram diferença estatística para o teste utilizado.

\section{CONCLUSÃO}

Com base no presente trabalho, foi possível concluir que as propriedades químicas do solo variam de acordo com cada tipo e uso. Os usos que demandam de produtos químicos apresentaram maiores valores para os elementos químicos estudados.

Foi possível observar que usos (soja, arroz e pastagem) alteraram as concentrações de $\mathrm{Ba}$ e $\mathrm{Zn}$, apresentando em alguns casos valores acima do máximo permitido pela legislação nacional, podendo esse aumento nas concentrações estar relacionado ao uso de agrotóxicos de que essas atividades necessitam. Sendo assim, pôde-se observar que os solos sob os usos de arroz, soja e pastagem apresentaram maior influência na concentração do elemento bário; já o fósforo teve maior influência dos solos sob o uso de pastagem e soja.
Tabela 4. Correlação entre os parâmetros analisados.

\begin{tabular}{lcccccc}
\hline & Altitude & Si & Mn & Zn & P & Ba \\
\hline Altitude & 1,00 & & & & & \\
Si & $-0,13$ & 1,00 & & & & \\
Mn & 0,24 & $-0,06$ & 1,00 & & & \\
Zn & 0,43 & 0,02 & 0,53 & 1,00 & & \\
P & 0,39 & $-0,03$ & 0,33 & 0,20 & 1,00 & \\
Ba & $-0,42$ & 0,21 & $-0,21$ & $-0,30$ & $-0,37$ & 1,00 \\
\hline
\end{tabular}

Tabela 5. Variação da concentração dos elementos químicos $\left(\mathrm{mg} / \mathrm{kg}^{-1}\right)$ em relação ao uso do solo na Bacia Hidrográfica do Rio Vacacaí-Mirim.

\begin{tabular}{|c|c|c|c|c|c|}
\hline Uso & $\mathrm{Ba}$ & $\mathrm{Mn}$ & $P$ & Si & $\mathrm{Zn}$ \\
\hline $\begin{array}{l}\text { Área } \\
\text { Urbana }\end{array}$ & $\mathrm{Ob}$ & $237,4 a$ & $205,5 c$ & $786.125 a$ & 48,31a \\
\hline Arroz & $3.115,9 a$ & $723,2 a$ & $286,6 \mathrm{cb}$ & $634.561 a$ & $65,63 a$ \\
\hline $\begin{array}{l}\text { Campo } \\
\text { Nativo }\end{array}$ & $66,7 b$ & $245,5 a$ & $268,8 \mathrm{cb}$ & $739.372 a$ & $90,54 a$ \\
\hline $\begin{array}{l}\text { Mata } \\
\text { Nativa }\end{array}$ & $\mathrm{Ob}$ & $845,8 a$ & $735,8 b$ & $660.283 a$ & $153,03 a$ \\
\hline Soja & $\mathrm{Oa}$ & $555,1 a$ & $1.200 a$ & $669.217 a$ & $155,32 a$ \\
\hline Pastagem & $2.101,5 \mathrm{ba}$ & $462,8 a$ & $1.398 \mathrm{a}$ & $758.549 a$ & $144,51 a$ \\
\hline
\end{tabular}

Médias seguidas pela mesma letra, minuscúla na coluna, não diferem entre si, pelo teste Duncan a 5\% de probabilidade.

\section{REFERÊNCIAS}

Abreu, C. A., Abreu, M. F., Berton, R. S. (2002). Análise química de solo para metais pesados. Tópicos em Ciência do Solo, 2(1), 645-692.

Azevedo, F. A., Chasin, A. A. M. (2003). Metais: Gerenciamento da toxicidade. São Paulo: Atheneu.

Bacellar, A. A. A., Marques, J. F., Skorupa, L. A., Ferraz, J. M. G., Silva, C. A. B., Fernandes, E. N., Fernandes Filho, E. I., Rodrigues, E. O., Lombardi Neto, F., Miranda, J. A., Lima, M. A., Neves, M. C., Pessoa, M. C. P. Y., Saito, M. L., Brandão, M. S. B., Gattaz, N. C., Ghini, R., Castro, V. L. S. D. , Bettio, W. (2003). Indicadores de sustentabilidade em agrossistemas. Jaguariúna: Embrapa Meio Ambiente.

Barbosa Filho, M. P., Snyder, G. H., Fageria, N. K., Datnoff, L. E., Silva, O. F. (2001). Silicato de Cálcio como fonte de silício para o arroz de sequeiro. Revista Brasileira de Ciência do Solo, 25(2), 325-330.

Bona, I. A. T., Sarkis, J. E. S., Salvador, V. L. R. (2007). Análise arqueométrica de cerâmica tupiguarani da região 
central do estado do Rio Grande do Sul, Brasil, usando fluorescência de raios x por dispersão de energia (EDXRF). Revista Química Nova. São Paulo 30(4), 785-790.

Carvalho, R., Goedert, W. J., Armando, M. S. (2004). Atributos físicos da qualidade de um solo sob sistema agroflorestal. Pesquisa Agropecuária Brasileira, 39(11), 1153-1155.

Casagrande, L. (2004). Avaliação do parâmetro de propagação de sedimentos do modelo de williams (1975) na bacia do rio Vacacai-Mirim com o auxílio de técnicas de geoprocessamento. Dissertação (Mestrado). Santa Maria: Centro de Tecnologia - UFSM.

Coelho, M. G. (1983). Variabilidade espacial de características físicas e químicas em um solo salinosódico. Ciência Agronômica, 14(2), 149-156.

Companhia de Pesquisa em Recursos Minerais - CPRM. (1994). Mapa hidrogeológico da folha de Santa Maria, SH.22-V-C-IV. Escala 1:100.000. Porto Alegre: Companhia de Pesquisa em Recursos Minerais - CPRM,

Companhia de Pesquisa em Recursos Minerais - CPRM. (2008). Mapa Geológico do Estado do Rio Grande do Sul. Escala 1:750.000. Brasília: Companhia de Pesquisa em Recursos Minerais - CPRM, <http://geobank.sa.cprm. gov.br>.

Companhia de Tecnologia e Saneamento Ambiental CETESB. (2012). Bário: Discrição e usos. Acesso em julho de 2012, <http://www.cetesb.sp.gov.br/userfiles/file/ laboratorios/fit/bario.pdf $>$.

Conselho Nacional do Meio Ambiente - CONAMA. (2009). Resolução $n^{\circ} 420$, de 28 de Dezembro de 2009. Acesso em fevereiro de 2011, <http://homologa. ambiente.sp.gov.br/aquiferos/CONAMA\%20 Resolucao\%202009_420.pdf>.

Empresa Brasileira de Pesquisas Agropecuária EMBRAPA. (1999). Sistema brasileiro de classificação de solos. Brasília: EMBRAPA.

Fonseca, A. C. (1999). Geoquímica dos Solos. Rio de Janeiro: Bertrand.

Hentges, S. C. (2009). Geologia da área da bacia hidrográfica do rio Vacacaí - Mirim, RS. Monografia (Trabalho Final de Graduação). Santa Maria: Centro de Tecnologia - UNIFRA.
Kabata-Pendias, A., Pendias, H. (1992). Trace elements in soil and plants. Florida: CRC Press.

Kemerich, P. D. C., Borba, W. F., Silva, R. F., Barros, G., Gerhardt, A. E., Flores, C. E. B. (2012). Valores anômalos de metais pesados em solo de cemitério. Ambi-Agua, 7(2), 140-156.

Kemerich, P. D. C., Schmachtenberg, N., Graepin, C., Borba, W. F., Flores, C. E. B., Flores, B. A. (2011). Características químicas de solo ocupado por necrópole. XXXI Jornada Acadêmica Integrada. Santa Maria: UFSM. Acesso em 01 de março de 2012, < http://portal.ufsm.br/ jai/anais/trabalho.html $>$.

Leinz, V., Amaral, S. E. (1989). Geologia Geral. São Paulo: Editora Nacional.

Marcolan, A. L. (2006). Suprimento e Absorção de Fósforo em Solos Submetidos a Diferentes Sistemas de Preparo. Tese (Doutorado). Porto Alegre: Centro de Ciências Rurais UFRGS.

Maud, M., Grassi Filho, H., Crusciol, C. A. C., Corrêa, J. C. (2003). Teores de silício no solo e na planta de arroz de terras altas com diferentes doses de adubação silicatada e nitrogenada. Revista Brasileira de Ciência do Solo, 27(5), 867-873.

Mengel, K. E., Kirkby, G. A. (1987). Further elements of importance. Worblaufen-Bern: International Potash Institute.

Minerais do Estado do Paraná S.A - MINEROPAR. (2004). Geoquímica do solo. Curitiba: MINEROPAR.

Minerais do Estado do Paraná S.A - MINEROPAR. (2005). Geoquímica de solo - horizonte B: relatório Final de projeto. Curitiba: MINEROPAR.

Neves, C. M. N., Silva, M. L. N., Curi, N., Cardoso, E. L., Macedo, R. L. G., Ferreira, M. M., Souza, F. S. (2007). Atributos indicadores da qualidade do solo em sistema agrossilvopastoril no noroeste do estado de Minas Gerais. Scientia Forestalis, 74(1), 45-53.

Paes, R. F. C. (2003). Caracterização do chorume produzido no aterro da Muribeca - PE. Dissertação (Mestrado). Campina Grande: Centro de Tecnologia URCG.

Pataca, L. C. M., Bortoleto, G. G., Bueno, M. I. M. S. (2005). Determinação de Arsênio em águas contaminadas 
usando fluorescência de raios-x por energia dispersiva. Revista Química Nova, 28(4), 579-582.

Pelozato, M. (2008). Valores de referência de Cádmio, Cobre, Manganês e Zinco para solos de Santa Catarina. Dissertação (Mestrado). Lages: Centro de Ciências Agro veterinárias - UNOESC.

Rocha, A. A. (2005). Controle e qualidade do solo. São Paulo: Manole, 2005.

Secretaria Estadual de Planejamento - SEPLAN. (1986). Levantamento dos recursos naturais. Rio de Janeiro: IBGE.

Silva, J. L. S., Maziero, L., Santos, E. F. (2004). Impactos da atividade humana sobre o solo - Aqüíferos. I Fórum Solos e Ambiente. Santa Maria: UFSM.

Silva, V. R., Reinert, D. J., Reichert, J. M. (2000). Densidade do solo, atributos químicos e sistema radicular do milho afetado pelo pastejo e manejo do solo. Revista Brasileira Ciência Solo, 24(2), 191-199.
Soares, I. A., Flores, A. C., Mendonça, M. M., Barcelos, R. P., Baroni, S. (2011). Fungos na biorremediação de áreas degradadas. Arquivos Instituto Biológico, 78(2), 341-350.

Streck, E. V., Kämpf, N., Dalmolin, R. S. D., Klamt, E., Nascimento, P. C., Schneider, P., Giasson, E., Pinto, L. F. S. (2008). Solos do Rio Grande do Sul. Porto Alegre: EMATER/RS - ASCAR.

Tito, G. A., Chaves, L. H. G., Guerra, H. O. C., Soares, F. A. L. (2011). Uso de bentonita na remediação de solos contaminados com Zinco: efeito na produção de feijão. Revista Brasileira de Engenharia Agrícola e Ambiental, 15(9), 917-923.

Wastowski, A. D., Rosa, G. M., Cherubin, M. R., Rigo, J. P. G. (2010). Caracterização dos níveis de elementos químicos em solo, submetido a diferentes sistemas de uso e manejo, utilizando espectrometria de fluorescência de raios-x por energia dispersiva (EDXRF). Revista Química Nova, 33(7), 1439-1452. 